\title{
Lane Density as Measure of Effectiveness of Multi lane Indian Highways under Heterogeneous Traffic Conditions
} (Traffic Engineering)

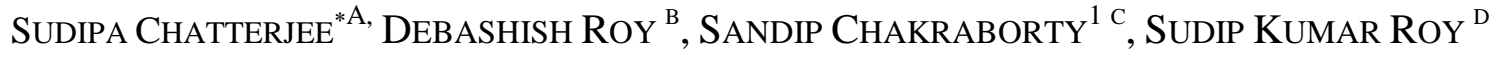

\begin{abstract}
The increment in the traffic flow demand has forced transport planners to increase the number of lanes of highways in order to provide better functional and operational facilities to the users. Measures of effectiveness (MOE) of a road system is one of the critical issues faced in highway planning and management. Level of service (LOS) is a qualitative measures describing the operational condition of a transportation facility. The LOS concept devised by US-HCM is unfit for direct implementation in Indian heterogeneous mixed traffic condition. This is mainly due to the heterogeneous traffic conditions and vastly unique driver behavior found on Indian highways. Thus a well-defined LOS criterion for heterogeneous traffic condition is utmost necessary. The vehicles prevailing under heterogeneous traffic vary widely in static and dynamic nature. An attempt has been made in this study to define the LOS criteria per lane basis on multilane highways in terms of traffic density, considering the distribution of traffic across the lanes. LOS being a classification problem has been obtained by Clustering technique in the present study. Kmeans clustering methods have been employed to classify LOS in six categories.
\end{abstract}

Keywords - Heterogeneous Traffic, Lane Distribution Factor, Stream Equivalency Factor, Clustering Technique, Level of Service.

\section{Introduction}

A multilane highway is a highway with at least two lanes for the exclusive use of traffic in each direction, with no control or partial control of access. With the growth of urbanization and increasing travel demand in India numerous two lane highways are being widened to four lanes and four lane highways to six

Sudipa Chatterjee, Former Post Graduate Student, CED

Indian Institute of Engineering Science and Technology Shibpur India

Debashish Roy, Research Scholar, CED

Indian Institute of Engineering Science and Technology Shibpur India

Sandip Chakraborty, Assistant Professor, CED

Indian Institute of Engineering Science and Technology Shibpur India

Sudip Kumar Roy, Professor, CED

Indian Institute of Engineering Science and Technology Shibpur India

${ }^{1}$ Corresponding Author lanes. Thus designing of new facilities and defining the operational condition of the existing facilities are thus becoming necessary to evaluate their serviceability.

The concept of level of service (LOS) was first introduced in US-Highway capacity manual (1965). Level of service is defined based on measure of effectiveness (MOE). According to US HCM (2010), density in terms of passenger cars per kilometer per lane is considered as serviceability measure for multilane highways. US- HCM defines six levels of service ranging from $\mathrm{A}$ to $\mathrm{F}$ where LOS $\mathrm{A}$ represents the best quality of traffic and LOS F the worst. The traffic condition prevailing in India is heterogeneous in nature. In such traffic condition the adaptation of methods of US-HCM is not appropriate.

As lane density is a true representative of heterogeneous traffic, in the present study LOS is predicted by the consideration of density per lane after converting the heterogeneous traffic flow to homogeneous traffic flow. The results obtained is applied on two new road sections and the LOS of the road sections were predicted. It was found that LOS not only varied from section to section but also from lane to lane under heterogeneous traffic condition.

\section{Related Works and Data Interpretation}

In India major multilane highways are the national highways which connects the country from north to south and east to west. Four important multilane corridors of India are selected for the present study. These corridors were selected from the four parts of the country mainly north south east west. Out of the selected sections two were four lane divided carriageway and two were six lane divided carriageway. Traffic data were collected by video photographic technique on typical week days. All data were collected in straight midblock sections with uninterrupted traffic flow. The sections studied were at plain terrain with paved shoulders. The lane width for 4 lane divided corridor was $3.75 \mathrm{~m}$ and for 6 lane divided highway was $3.50 \mathrm{~m}$.

\section{A. Level of Service}

Over the years many researchers have worked on different LOS criteria. Drew (1968) [5] developed an energy momentum approach to LOS. He suggested that acceleration noise could 
Proc. of the Fourth International Conference on Advances in Civil, Structural and Environmental Engineering - ACSEE 2016. Copyright $(\odot$ Institute of Research Engineers and Doctors. All rights reserved.

ISBN: 978-1-63248-114-6 doi: 10.15224/ 978-1-63248-114-6-18

describe the discomfort of a driver better than travel time or average speed. Acceleration noise is defined as the standard deviation of accelerations (including deceleration as negative acceleration). Kita and Fujiwara (1995) [8] stated that quantitative measures of the level of service are merely the characteristics of traffic operating conditions. But they not necessarily show the quality of service perceived by the drivers. The authors tried to establish a relationship between drivers' perception and LOS. Marwah and Singh (2000) [13] used simulation model to estimate LOS for a two lane unidirectional road. They considered journey speed of cars and motorized two wheelers, concentration or density and road occupancy as service measures. Luttinen (2001) [11] identified Percent time spent following (PTSF) as the most important performance measure for two lane highways. He found in his study that the PTSF values are lower on Finnish two lane highway than that suggested by US-HCM (2000). Surasak et al. (2004) [17] studied the platoon characteristics on a multilane highway in Japan. They found that traffic density does not adequately reflect a driver's perception on serviceability of a highway. Thus based on platoon rate they suggested four level of service. Flannery et al. (2006) [6] modeled driver perception on rural freeways by using probit models. The results obtained were significantly different from that mentioned in US-HCM. Semeida (2013) [15] carried out a study on the multilane highways of Egypt. He established a relationship between the road geometrics, heavy vehicle proportion and LOS of a road segment. The author developed an Artifical Neural Network model to estimate LOS and capacity.

\section{B. Lane Distribution Factor}

Golias and Tsamboulas (1999) [7] found that the distribution of traffic volume to individual lanes is an important factor of traffic analysis for multilane highway. Ning Wu (2005) [14] carried out his study on lane distribution in the motorways of Germany. He noticed a significant difference in lane flow distribution between the motorways of Germany and North America. Lee and Park (2012) [12] studied lane use distribution under uncongested to transition as well as transition to congested conditions. Regression models were proposed taking Lane distribution as a function of density measure. From the present study conducted it was found that cars prefer to move along the median lane while two wheelers and light vehicles prefer the shoulder lane. Heavy vehicles generally adhere to median lane in four lane highways and middle lane in six lane highways. The lane distribution factor was estimated as -

$$
L D F_{i}=\frac{V_{i}}{V}
$$

Where LDFi $=$ Lane Distribution Factor for ith lane, $\mathrm{Vi}=$ Traffic flow rate for ith lane $(\mathrm{Veh} / \mathrm{h}), \mathrm{V}=$ Total Traffic flow rate $(\mathrm{Veh} / \mathrm{h})$

In this study LDF was predicted as a function of flow rate. It was found that increase in flow rate tends to equalize the LDF. Logarithmic models for different traffic composition on
4 and 6 lane highways were developed to estimate the distribution factor. Table I present the developed single variable regression model.

TABLE I: Single Variable Regression Model of Lane Distribution Factor

\begin{tabular}{|c|c|c|}
\hline Road Section & $\begin{array}{l}\text { Estimated Single Variable } \\
\text { Model }\end{array}$ & Statistical Parameters \\
\hline $\begin{array}{l}\text { NH } 6 \\
4 \text { lane divided } \\
\text { highway }\end{array}$ & $\begin{array}{l}\mathrm{LDF}_{\mathrm{MED}}=0.177 \ln (\mathrm{V})- \\
0.852 \\
\mathrm{LDF}_{\mathrm{SHO}}=\left(1-\mathrm{LDF}_{\mathrm{MED}}\right)\end{array}$ & $\begin{array}{l}\text { Adjusted } \mathrm{R}^{2}=0.732, \mathrm{SEE} \\
=0.019\end{array}$ \\
\hline $\begin{array}{l}\mathrm{NH} 45 \\
4 \text { lane divided } \\
\text { highway }\end{array}$ & $\begin{array}{l}\mathrm{LDF}_{\mathrm{MED}}=0.109 \ln (\mathrm{V})- \\
0.3341 \\
\mathrm{LDF}_{\mathrm{SHO}}=\left(1-\mathrm{LDF}_{\mathrm{MED}}\right)\end{array}$ & $\begin{array}{l}\text { Adjusted } \mathrm{R}^{2}=0.784, \mathrm{SEE} \\
=0.020\end{array}$ \\
\hline $\begin{array}{l}\mathrm{NH} 8 \\
6 \text { lane divided } \\
\text { highway }\end{array}$ & $\begin{array}{l}\mathrm{LDF}_{\mathrm{MED}}=0.037 \ln (\mathrm{V})+ \\
0.096 \\
\mathrm{LDF}_{\mathrm{MID}}=0.034 \ln (\mathrm{V})+ \\
0.179 \\
\mathrm{LDF}_{\mathrm{SHO}}=\left[1-\left(\mathrm{LDF}_{\mathrm{MED}}+\right.\right. \\
\left.\left.\mathrm{LDF}_{\mathrm{MID}}\right)\right]\end{array}$ & $\begin{array}{l}\text { Adjusted } \mathrm{R}^{2}=0.701, \mathrm{SEE} \\
=0.007 \\
\text { Adjusted } \mathrm{R}^{2}=0.613, \mathrm{SEE} \\
=0.007\end{array}$ \\
\hline $\begin{array}{l}\text { NH } 10 \\
6 \text { lane divided } \\
\text { highway }\end{array}$ & $\begin{array}{l}\mathrm{LDF}_{\mathrm{MED}}=0.187 \ln (\mathrm{V})- \\
0.910 \\
\mathrm{LDF}_{\mathrm{MID}}=-0.226 \ln (\mathrm{V})+ \\
1.956 \\
\mathrm{LDF}_{\mathrm{SHO}}=\left[1-\left(\mathrm{LDF}_{\mathrm{MED}}+\right.\right. \\
\left.\left.\mathrm{LDF}_{\mathrm{MID}}\right)\right]\end{array}$ & $\begin{array}{l}\text { Adjusted } R^{2}=0.506, \\
S E E=0.050 \\
\text { Adjusted } R^{2}=0.796, \\
S E E=0.031\end{array}$ \\
\hline \multicolumn{3}{|c|}{$\begin{array}{l}\mathrm{LDF}_{\mathrm{MED}}=\text { Distribution on Median Lane; } \mathrm{LDF}_{\mathrm{MID}}=\text { Distribution on Middle } \\
\text { Lane; } \mathrm{LDF}_{\mathrm{SHO}}=\text { Distribution on Shoulder Lane; V = Flow Rate }(\mathrm{Veh} / \mathrm{hr}) \text {; } \\
\text { SEE = Standard Error of Estimate }\end{array}$} \\
\hline
\end{tabular}

\section{Stream Equivalency Factor}

Indian traffic varies widely in static and dynamic characteristics. Conventionally to estimate traffic volume under such heterogeneous condition it is essential to convert the traffic flow in terms of equivalent numbers of passenger car units (PCU). To simplify this process of conversion Dhamaniya and Chandra (2013) developed the concept of Stream Equivalency Factor. The authors defined Stream Equivalency Factor (SEF) as the ratio of Flow in Vehicles per hour to Flow in PCU per hour. Since SEF is a ratio of Volume in PCU/hr and Volume in Veh/hr, a variation of PCU values impacts the SEF values. Chandra and Kumar (2003) evaluated PCU as-

$$
P C U_{i}=\left(V_{c} / V_{i}\right) /\left(A_{c} / A_{i}\right)
$$

Where PCUi $=$ the PCU for the vehicle type $\mathrm{i}, \mathrm{Vc} / \mathrm{Vi}=$ speed ratio of CS (standard car) to $i$ th type of vehicles, $\mathrm{Ac} / \mathrm{Ai}$ $=$ ratio of their physical rectangular area or projected area. As the ratio of physical area remain almost constant for a vehicle type the variation in speed effects the PCU values. In the present study relationship between Stream Equivalency Factor with the variation of Flow (Veh/h) was observed. From the study it was found that SEF decreases with increase in flow rate.

The stream equivalency factor is highly influenced by the proportion of heavy vehicles. In case of 4 lane divided highway two different conditions were observed, one when the proportion of heavy vehicles (HV i.e. $\mathrm{HCV}+\mathrm{MAV}$ ) was less than $10 \%$ (for $\mathrm{NH} \mathrm{45)} \mathrm{and} \mathrm{other} \mathrm{when} \mathrm{the} \mathrm{proportion} \mathrm{of} \mathrm{heavy}$ vehicle was more than $10 \%$ (for NH 6). Similarly, for 6 lane 
Proc. of the Fourth International Conference on Advances in Civil, Structural and Environmental Engineering - ACSEE 2016. Copyright ( $\odot$ Institute of Research Engineers and Doctors. All rights reserved.

ISBN: 978-1-63248-114-6 doi: 10.15224/ 978-1-63248-114-6-18

divided highway the two conditions were for proportion of heavy vehicles of less than $20 \%(\mathrm{NH} \mathrm{10})$ and proportion of heavy vehicles more than $20 \%(\mathrm{NH} \mathrm{10)}$. A polynomial relationship was established with SEF and flow rate (Veh/h) for varying proportion of heavy vehicles. The general form of the equation is -

$$
S E F=a f^{2}+b f+c
$$

Where $\mathrm{a}, \mathrm{b}$ are regression co-efficient and $\mathrm{c}$ regression constants and $\mathrm{f}$ is the flow rate in $\mathrm{Veh} / \mathrm{h}$. The regression model developed for predicting SEF is shown in Table II.

Table II: Predicting Stream Equivalency Factor as a function of Flow Rate

\begin{tabular}{|l|l|l|l|l|l|}
\hline \multirow{2}{*}{ Road Section } & \multicolumn{2}{|l|}{$\begin{array}{l}\text { Regression } \\
\text { Coefficients }\end{array}$} & $\begin{array}{l}\text { Regression } \\
\text { Constants }\end{array}$ & $\begin{array}{l}\text { Adjusted } \\
\mathrm{R}^{2}\end{array}$ \\
\cline { 2 - 5 } & $\boldsymbol{a}$ & $\boldsymbol{b}$ & $\boldsymbol{c}$ & Value \\
\hline $\begin{array}{l}\text { 4 lane } \\
\text { divided } \\
\text { highway }\end{array}$ & $\% \mathrm{HV}>10 \%$ & $7 \times 10^{-7}$ & -0.0023 & 4.797 & 0.984 \\
\cline { 2 - 5 } & $\% \mathrm{HV} \leq 10 \%$ & $3 \times 10^{-7}$ & -0.0009 & 1.905 & 0.865 \\
\hline $\begin{array}{l}\text { 6 lane } \\
\text { divided } \\
\text { highway }\end{array}$ & $\% \mathrm{HV}>20 \%$ & $1 \times 10^{-6}$ & -0.0037 & 5.687 & 0.908 \\
\cline { 2 - 5 } & $\% \mathrm{HV} \leq 20 \%$ & $2 \times 10^{-8}$ & -0.0002 & 1.891 & 0.866 \\
\hline
\end{tabular}

\section{Clustering Technique}

Lingras (1995) [9] compared traffic data set by grouping of traffic patterns by Hierarchical Agglomerative Clustering and Kohonen Neural Network Methods. Lingras (2001) [10] suggested that Genetic Algorithms approach provides better results than Hierarchical Agglomerative Clustering in classifying highway sections when the number of groups are small. Bhuyan and Rao (2012) [1] applied k-means and kmedoid clustering for defining LOS criteria of urban streets in Indian condition and found k-medoid to be more efficient.

\section{a. k- means clustering:}

The objective of $\mathrm{k}$-means clustering is to find a partition in which objects within each cluster are as close to each other as possible, and as far from objects in other clusters as possible. Each cluster in the partition is defined by its member objects and centroid. The point to which the sum of distances from all objects in that cluster is minimized is the centroid.

\section{b. Determination of Optimum Number of Clusters:}

In the first step of clustering the three validation parameters were interpreted to determine the optimum number of clusters.

Calinski Harabasz values:

Davies-Bouldin Index:

Gap Values:

\section{c. Validation of Clusters:}

Silhouette Value: The silhouette value for each point is a measure of how similar that point is to points in its own cluster, when compared to points in other clusters. It is thus a useful interpretation and validation tool for measuring the consistency within clusters of data. The silhouette value for the ith point, $\mathrm{Si}$, is defined as -

$$
S_{i}=\left(b_{i}-a_{i}\right) / \max \left(a_{i}, b_{i}\right)
$$

Where ai is the average distance from the ith point to the other points in the same cluster as $i$, and bi is the minimum average distance from the ith point to points in a different cluster, minimized over clusters. The silhouette value ranges from -1 to +1 . A high silhouette value (greater than or equal to 0.71 ) indicates that $\mathrm{i}$ is well-matched to its own cluster, and poorly-matched to neighboring clusters.

\section{Analysis and Discussion}

The heterogeneous traffic flow rate was converted to a homogeneous flow rate by multiplying it with the Lane Distribution Factor and the Stream Equivalency Factor as obtained earlier in the study.

$$
\begin{aligned}
& \text { Flow rate }(\mathrm{PCU} / \mathrm{h} / \mathrm{ln})=(\text { Flow rate }(\text { Veh } / \\
& \text { h) } x \text { LDF } \times S E F)
\end{aligned}
$$

Thereafter per lane density was also calculated from the lane flow rate and average speed of the same lane.

The collected average stream speed data were classified into five groups by $\mathrm{k}$ means clustering performed in MATLAB 2015a. Clustering of Average Stream Speed being a single variable classification problem, both the axes represent the Average Stream Speed $(\mathrm{km} / \mathrm{h})$. Figure 5 shows the average stream speed cluster by k-means clustering.

The silhouette value obtained was quite high (0.730) which indicated that the cluster of average stream speed was strong. The height of the silhouette represents the number of objects in that cluster. It was found that among the five classes, heights of speed category II and III is higher than other categories. This signifies that from the data obtained the average stream speed ranges obtained mostly lie between $53-62 \mathrm{~km} / \mathrm{h}$. The Silhouette plot obtained is shown in Figure 1.

The density obtained corresponding to the speed ranges was further classified into groups. The optimum number of clusters suggested by Callinski Harabasaz values and Davies Bouldin Index is 6 and Gap Value is 1 respectively. So the optimum number of clusters adopted for the study is 6 . Similar to the Average Stream Speed classification as categorizing Density is a single variable classification problem a $45^{\circ}$ plot is obtained (Figure 2) after clustering of the data under different speed ranges. In Table III the density ranges for LOS categories are mentioned.

The Silhouette values for level of service considering density as measure of effectiveness for the different average speed range are shown in Figure 3. The figure also indicates the density points that do not belong to a specific cluster but lie in between the clusters. From the heights of the silhouette plot it was seen that at higher speed ranges vehicles mostly travelled at a service level A and B. 
Proc. of the Fourth International Conference on Advances in Civil, Structural and Environmental Engineering - ACSEE 2016. Copyright $(\odot$ Institute of Research Engineers and Doctors. All rights reserved.

ISBN: 978-1-63248-114-6 doi: 10.15224/ 978-1-63248-114-6-18
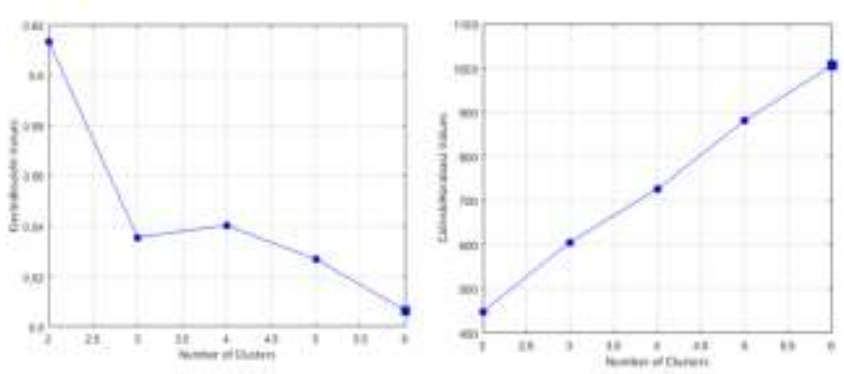

(a)

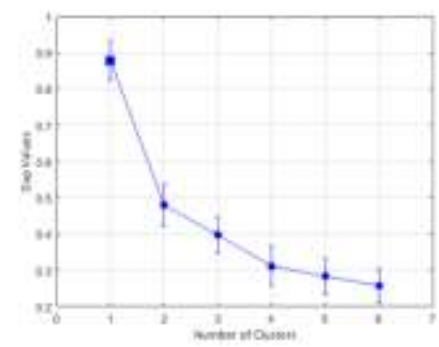

(c)

Fig. 1: Determining Optimum number of Clusters (a) Calinski Harabasz Value (b) Davies-Bouldin Values (c) Gap Values

Table III: Density ranges of LOS categories using k-means clustering

\begin{tabular}{|c|c|c|c|c|c|c|}
\hline $\begin{array}{c}\text { Average Stream } \\
\text { Speed Range } \\
(\mathrm{km} / \mathrm{h})\end{array}$ & \multicolumn{7}{|c|}{ Lane Density (PCU/km/ln) } \\
\cline { 2 - 7 } & $\mathrm{A}$ & $\mathrm{B}$ & $\mathrm{C}$ & $\mathrm{D}$ & $\mathrm{E}$ & $\mathrm{F}$ \\
\hline $47-53$ & $\leq 10$ & $>10-16$ & $>16-24$ & $>24-33$ & $>33-41$ & $>41$ \\
\hline $53-57$ & $\leq 10$ & $>10-16$ & $>16-24$ & $>24-31$ & $>31-39$ & $>39$ \\
\hline $57-62$ & $\leq 10$ & $>10-16$ & $>16-23$ & $>23-30$ & $>30-37$ & $>37$ \\
\hline $62-68$ & $\leq 10$ & $>10-16$ & $>16-22$ & $>22-29$ & $>29-36$ & $>36$ \\
\hline $68-74$ & $\leq 10$ & $>10-16$ & $>16-21$ & $>21-28$ & $>28-35$ & $>35$ \\
\hline
\end{tabular}

\section{Application of the Model}

In order to apply the model obtained data collected from two different locations of four lane (NH 3) and six lane (NH 8 at $\mathrm{km} \mathrm{165)}$ highways were studied. Both the peak and off peak hour were considered for evaluating the serviceability of the road sections studied. The geometric features of the road sections were same as that of the study sections though the variation in traffic composition is noticed. In NH 3 the traffic mainly consisted of CB (28\%), $2 \mathrm{w}(27 \%)$ and LCV (24\%). Only $10 \%$ of the traffic comprised of CS and $2 \%$ of $\mathrm{HCV}$. At km 165 of NH 8 the proportion of CS (24\%) and CB $(23 \%)$ is more compared to $2 \mathrm{w}(12 \%)$ and $\mathrm{HCV}(12 \%)$. The lane distribution factor and stream equivalency factor evaluated from the described models were used to convert the hourly flow rate to flow rate per lane in PCU/h/ln. The volume was divided by the average stream speed to obtain density in $\mathrm{PCU} / \mathrm{km} / \mathrm{ln}$.
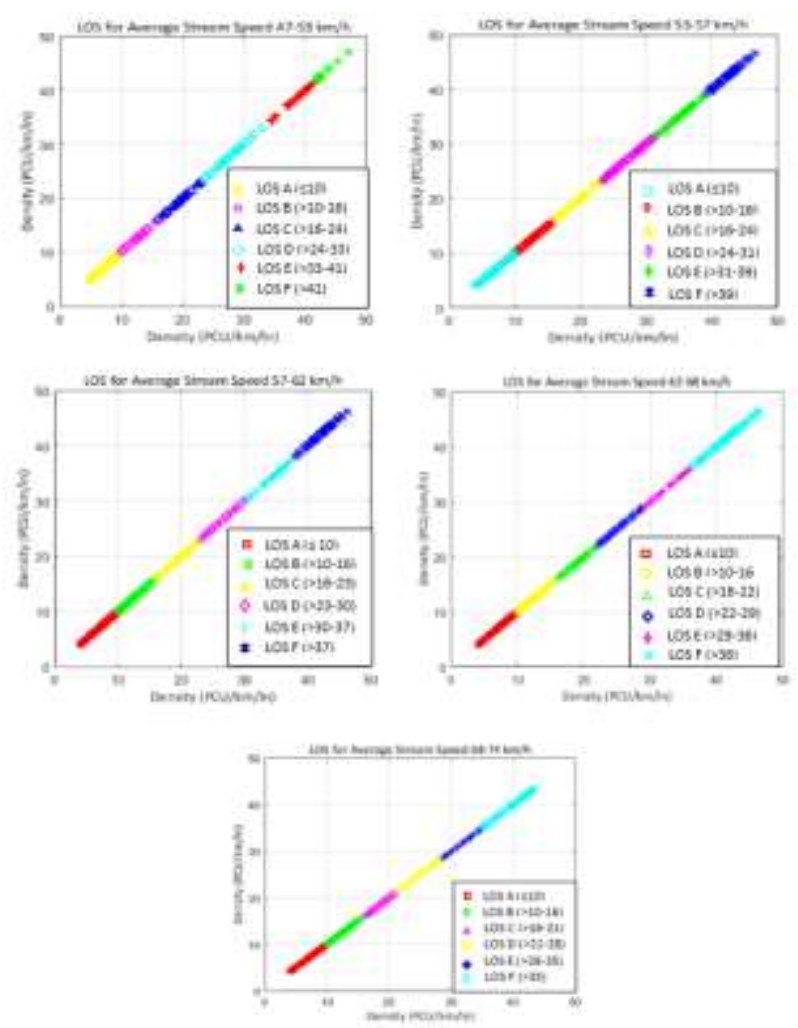

Fig. 2: k-means clustering of Density for LOS of Multilane Highways
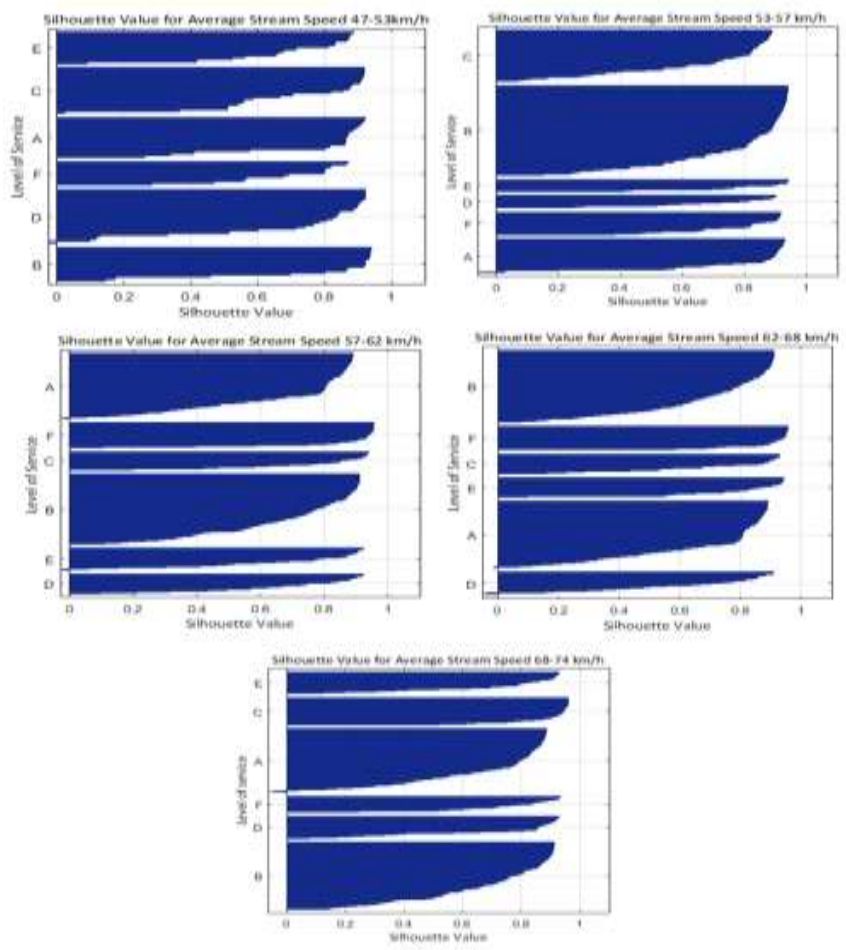

Fig. 3: Silhouettes plots for LOS categories of Multilane Highways 
Proc. of the Fourth International Conference on Advances in Civil, Structural and Environmental Engineering - ACSEE 2016. Copyright $(\odot$ Institute of Research Engineers and Doctors. All rights reserved.

ISBN: 978-1-63248-114-6 doi: 10.15224/ 978-1-63248-114-6-18

\section{Summary and Future Research}

In the study evaluation of the serviceability of a road section lane wise was approached. From the study conducted it was observed that heterogeneous traffic is not equally distributed across the road width rather different vehicle types induce different lane choice and lane usage. To evaluate the lane distribution single variable models were developed for four and six lane highways. Lane distribution factor was expressed as a function of flow rate. Another challenge to the study was to convert the heterogeneous traffic stream to homogeneous traffic stream. The Stream equivalency factor was evaluated to successfully convert the traffic flow rate from Vehicle /h to PCU/h. At the first stage of classifying LOS the average stream speed obtained from the study sections were classified. After interpreting different clustering validation methods, the corresponding density of each speed range groups were classified under six categories. It was observed that with increase in speed range more vehicles travelled at a better service levels.

The results of density classification were applied by data from two different locations. From the results obtained it was observed that the serviceability varied not only different road sections but also from lane to lane under heterogeneous traffic conditions.

This study only focused on a specified speed range and on plain terrain on multilane highways with paved shoulder. The variation in type and width of shoulder and terrain type should be considered for further research. Additional research could be carried out for higher as well as lower values of average stream speeds.

\section{Acknowledgement}

Authors sincerely acknowledge the CSIR-Centre Road Research Institute, New Delhi, India in conducting the research work for which this study was carried out.

\section{References}

[1] Bhuyan PK, Rao KVK (2012) Defining Los criteria of urban streets using GPS data: k-means and k-medoid clustering in Indian context. Transport. 27(2):149-157.

[2] Dhamaniya A, Chandra S (2013) Concept of Stream Equivalency Factor for Heterogeneous Traffic on Urban Arterial Roads. Journal of Transportation Engineering, ASCE. 139:1117-1123.

[3] Dell'Orco M, Mellano M (2013) A New User-Oriented Index Based on a Fuzzy Inference System for Quality Evaluation of Rural Roads. Computer-Aided Civil and Infrastructure Engineering, 28(8):635-647.

[4] Desgraupes B (2013) Clustering Indices, Package clusterCrit for R. (University Paris Ouest, Lab Modal'X)

[5] Drew D.R. (1968) Traffic Flow Theory and Control. (McGraw-Hill, New York)

[6] Flannery A, Wochinger K, Martin A (2005) Driver assessment of service quality on urban streets. Transportation Research Record.1920:25-31.

[7] Golias J, Tsamboulas D (1995) Macrolevel Estimation of Highway Lane Usage. Journal of Transportation Engineering, ASCE. 121:40-49.
[8] Kita H, Fujiwara E (1995) Reconsideration on the level of service and a proposed measure. Proceedings of 15th Annual Meeting of JSTE (Japan), 25-28.

[9] Lingras P (1995) Classifying highways: Hierarchical grouping versus kohonen neural networks. Journal of Transportation Engineering, ASCE. 121(4):364-368.

[10] Lingras P (2001) Statistical and genetic algorithms classification of highways. Journal of Transportation Engineering, ASCE. 127(4):237243.

[11] Luttinen R.T (2001) Percent Time Spent Following as Performance Measure for Two-Lane Highways. Transportation Research Record. 1776:52-59.

[12] Lee J, Park B B (2012) Determining Lane Use Distributions Using Basic Freeway Segment Density Measures. Journal of Transportation Engineering, ASCE. 138:210-217.

[13] Marwah B. R. and Singh B (2000) Level of service classification for urban heterogeneous traffic: A case study of Kanpur metropolis. Fourth international symposium on Highway Capacity (Hawaii).

[14] Ning Wu (2005) Impact of traffic regulation on lane flow-distribution and capacity of motorways. The Website Server of the Ruhr University Bochum. (Institute for Traffic Engineering, Ruhr University Bochum, Germany.)

[15] Semeida A M (2013) New models to evaluate the level of service and capacity for rural multi-lane highways in Egypt. Alexandria Engineering Journal. 52:455-466.

[16] Shao M, Sun L (2010) United evaluation model of traffic operation level for different types of urban road. Journal of Tongji University. 38(11):1593-1598

[17] Surasak T, Okura I, Nakamura F (2004) Measuring Level of Services on Multilane Expressways by Platoon Parameters. Journal of Infrastructure Planning and Management, JSCE. 772/IV-65:23-32.

\section{About Author (s):}

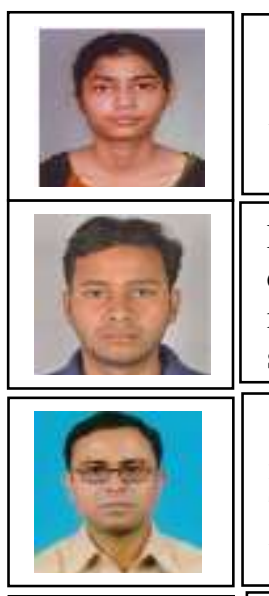

Sudipa Chatterjee works on traffic behaviour on multilane road, road safety of Indian Interurban roads, and application of microsimulation on Indian mix-traffic.

Debashish Roy works on traffic behaviour on congested Indian urban roads, Traffic flow modelling and application of microsimulation on Indian mix-traffic.

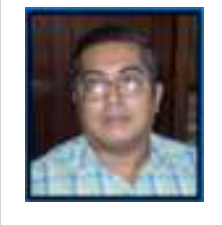

Sandip Chakraborty works on traffic flow modelling on congested Indian urban roads, Traffic safety of Vulnerable Road users and traffic simulation study on Indian mix-traffic.

Sudip Kumar Roy works on transportation planning and modelling for cities of developing countries, traffic flow modelling on heterogeneous mix-traffic conditions, transportation system performance evaluation, and Road safety. 